\title{
Lucky Girls: Unintentional Avoidance of Adolescent Pregnancy Among Low-Income African-American Females
}

\author{
Kristy K. Martyn, Sally A. Hutchinson, and Jacquelyn H. Martin
}

PURPOSE. To describe lucky adolescents who unintentionally avoid pregnancy. DESIGN AND METHODS. The second phase of a descriptive qualitative study in which 17 lowincome African-American females ages 19 to 26 participated in open-ended interviews on how they avoided pregnancy as adolescents.

RESULTS. Constant comparative analysis revealed that five of the girls avoided pregnancy because they were "lucky" that others insisted they use contraceptives. These lucky girls were unaware of sexual risks, but used contraceptives because they complied with decisions made by their parents, grandparents, and partners. PRACTICE IMPLICATIONS. Lucky girls are at risk for adolescent pregnancy because they abdicate decision making to others and are likely to be overlooked in practice because they are using contraceptives. Promoting self-protection includes assessment, knowledge, skills-building strategies, and health-promoting contracts between the nurse and adolescent.

Search terms: Adolescence, blacks, contraception, pregnancy

Accepted for publication October 16, 2001.
Kristy K. Martyn, PhD, RN, CS, CPNP, is Assistant Professor, School of Nursing, University of Michigan, Ann Arbor, MI. Sally A. Hutchinson, PhD, RN, FAAN, is Professor, University of Florida Health Science Center, Jacksonville, FL. Jacquelyn H. Martin, MS, RN, CS, is a Family $\mathcal{E}$ Pediatric Nurse Practitioner, Children's Health Care of Atlanta: KidCare, East Point, GA.

D uring the last decade, African-American adolescent pregnancy (Henshaw, 1999; Kaufmann et al., 1998) and live birth rates (Ventura, Martin, Curtain, \& Matthews, 1998) have declined significantly due to reductions in adolescent sexual activity (Brener \& Collins, 1998) and increases in adolescent contraceptive use (Brindis, 1999; Sonenstein, Ku, Lindberg, Turner, \& Pleck, 1998). In comparison with white and Hispanic adolescents, AfricanAmerican adolescents have experienced the most significant declines. Fewer African-American adolescent girls are having sexual intercourse (Lindberg, Boggess, Porter, \& Williams, 2000), and the birth rate of African-American females ages 15 to 19 years decreased by $21 \%$ between 1991 and 1996 (Ventura et al.).

Explanations of these changes in adolescent sexual and reproductive behavior are developing. The extensive literature on adolescent pregnancy includes comparisons of never-pregnant adolescents to those who have been pregnant. For example, birth intentions (Trent \& Crowder, 1997) and communication with parents about sex (Pistella \& Bontati, 1998) were similar for both groups. However, never-pregnant adolescents had a more internal locus of control (Morgan, Chapar, \& Fisher, 1995) and a stronger orientation to the future (Freeman \& Rickels, 1993).

In our descriptive, qualitative study we extend the existing literature by examining the experiences of low-income, African-American adolescent girls who unintentionally avoided pregnancy. Our analysis builds on previous work that focused on intentional pregnancy avoidance. In the first phase of our adolescent pregnancy avoidance study, a grounded theory was developed that described how the majority of the low-income, African-American adolescent participants, whom we 


\section{Lucky Girls: Unintentional Avoidance of Adolescent Pregnancy Among Low-Income African- American Females}

called "tough" girls, intentionally avoided adolescent pregnancy. The tough girls recognized sexual risks, rejected those risks, and strategically protected themselves from pregnancy as adolescents (Martyn \& Hutchinson, 2001). During the development of this grounded theory, we discovered that some of the participants were not intentionally avoiding pregnancy. Some of the girls described themselves as being "lucky" that they did not become pregnant as adolescents. In the second phase of this study presented here, we focus on these lucky girls and how they unintentionally avoided adolescent pregnancy.

\section{Social Context}

Our analysis of unintentional pregnancy avoidance of the girls in this study is informed by the symbolic interactionist perspective (Blumer, 1969). Symbolic interactionism (SI) focuses on individual development and societal context as complementary aspects of human experience (Mead, 1934). Both the self and the world are always changing through social interaction and, therefore, can be understood only within social context (Hutchinson, 1993). Based on the National Longitudinal Study of Adolescent Health study, Resnick et al. (1997) concluded that, "of the constellation of forces that influence health-risk behavior, the most fundamental are the social contexts in which adolescents are embedded; the family and school contexts are among the most critical" (p. 823).

The concepts of social and cultural capital (learning that occurs through informal social interaction with others that influences monetary activities) further our understanding of the social influences experienced by these girls. Kelly (1994) applied these concepts to poor innercity African-American adolescent pregnancy in an ethnographic study. She viewed the lack of multiplexity, the "degree to which [social networks] are composed of persons with differing social status," (p. 99) as a primary contributing factor in adolescent childbearing among the impoverished African-American girls in her study. Others have found African-American adolescents with low social support were more likely to experience casual sex, coercion for unwanted sex, sexually transmitted diseases, and other negative sexual risk outcomes than those with high social support (St. Lawrence, Brasfield, Jefferson, Allyene, \& Shirley, 1994). On the other hand, the decrease in sexual activity and pregnancy among adolescent girls who participate in sports has been linked to the positive influence of coaches and teammates (Miller, Sabo, \& Farrell, 1998; Sabo, Miller, Farrell, Melnick, \& Barnes, 1999), which is especially significant in light of recent reports that $58 \%$ of adolescents participate on school sports teams (Lindberg et al., 2000).

\section{Psychosocial and Developmental Perspectives}

Psychosocial and developmental perspectives informed our qualitative study analysis. According to Gilligan (1982), female development of identity is blended with intimacy. The need for love, independence, and acceptance is essential to adolescent girls' development of identity and self-esteem. For female adolescents, the high value placed on caring and relationships can foster the desire for sexual relations. Having sex may serve as a statement of an adolescent female's identity definition, where she defines herself in relation to others as a partner. In light of Gilligan's work on female development, sexual decision making for adolescent females needs to be reconsidered. Gullone and Moore (2000) discovered that adolescent judgments of risk, personality (females showed greater agreeableness and conscientiousness than males), age, and gender (younger adolescents and females engaged in less risky behaviors and rated risk behaviors as more risky than older adolescents or males) were significant predictors of risk behavior. The importance of love and acceptance for females suggests that women may abdicate decisions about contraception to avoid jeopardizing relationships with significant others.

The concept of self-regulation, defined as the "capacity to plan, guide, and monitor ... behavior from within and flexibly according to changing circumstances" (Diaz, Neal, \& Amaya-Williams, 1990, p. 130) and the role of interpersonal communication in the development of self- 
regulation (Vygotsky, 1962, 1978) are pertinent to exploration of the interpersonal interactions of the lucky girls in this study. According to Vygotsky, adults interact with children to assist them in developing independent problem solving by communicating learned concepts to the child, who integrates them with his/her personal experiences.

Yowell (1997) applied these concepts to communication about sexuality between early adolescent girls and their mothers. Development of sexual responsibility was found to be dependent on the mother's knowledge of sexuality issues and communication style, and on the daughter's willingness to integrate knowledge from her mother with her own personal experiences. Yowell found that development of self-regulation was curtailed with some mothers and daughters when "the power-assertive communication style and passive engagement style dyadic interactions represented a unilateral transmission of information from mother to daughter" (p. 187). The need for external control and compliance with parental expectations served to motivate the passively engaged girls to communicate with their mothers about sexuality issues. High parental monitoring (Li, Feigelman, \& Stanton, 2000) and family and school connectedness (Lindberg et al., 2000; Resnick et al., 1997) also have been found to be inversely related to adolescent sexual risk taking. For passively engaged girls, the connections between the expert knowledge given by adults and their own novice experiences do not occur, and these girls continue to rely on adults to regulate their behavior. As a result, perceptions of risk, intrinsic motivation, and self-protective decision making do not develop, and the girls are potentially more vulnerable than other girls to risky influences.

Our descriptive qualitative research focuses on lucky girls who exhibit a passively engaged style. With a more in-depth understanding of these young women, it is possible to suggest situation- and personality-specific interventions aimed to decrease risky sexual behavior.

\section{Methods}

The purposive subsample used in this study is part of an adolescent pregnancy avoidance study in which we interviewed young, low-income African-American women who did not become pregnant before age 19. In the first phase of the study, 17 African-American women 19 to 26 years old responded to fliers posted at urban public health department clinics and universities, and participated in in-depth interviews concerning their perceptions about not getting pregnant during adolescence. These semistructured interviews focused on pregnancy avoidance influences, decision making, and relationships with significant individuals. Saturation of conceptual information determined the sample size and theoretical sampling advanced data analysis.

The importance of love and acceptance for females suggests that women may abdicate decisions about contraception to avoid jeopardizing relationships with significant

\section{others.}

Five of the 17 women, the focus of the second phase of the study reported here, revealed that they unintentionally avoided adolescent pregnancy. They were 20 to 26 years old at the time of the interviews. Two were from two-parent homes, 2 from mother-headed homes, and 1 was raised by her grandmother. Average family income was $\$ 12,580$, and average family size was five. Four received education after high school (2-5 years of college or technical school), and 1 was married at the time of the study. All girls were raised in metropolitan cities in the South. None of the girls became pregnant or had babies before she was 19 years old. One was sexually active at the age of 13 , and the others by the time they were 16. All the girls used contraceptives.

Georgia State University and the University of Michigan's Institutional Review Boards approved the research 


\section{Lucky Girls: Unintentional Avoidance of Adolescent Pregnancy Among Low-Income African-}

American Females

protocols. In the first phase of the study, two of the authors conducted and audiotaped five focus groups and seven individual interviews that explored the experience of avoiding adolescent pregnancy. In the first phase, 3 of the 5 girls described here were individually interviewed for 25- to 45-minute sessions, and the other 2 participated in two focus groups totaling approximately 4 hours. Following completion of data collection for the first phase, 1 participant who demonstrated characteristics typical of the lucky girls and 1 participant who depicted typical tough-girl characteristics participated in follow-up, in-depth individual interviews. These 2-hour, semistructured interviews focused on communication about sex, relationships, sexual activity, and contraceptive use and provided additional data for comparative analysis and validity checks.

\section{Data Analysis}

The constant comparative method guided the analysis of interview data, including substantive and theoretical coding, memoing, sorting, and theoretical sampling (Glaser, 1978, 1992). Open coding, line-by-line scrutiny of the data resulted in identification of substantive codes, which were compared to other data; those that appeared to be similar were assigned to categories. The simultaneous process of data collection and analysis along with validation with participants and colleagues contributed to validity (Lincoln \& Guba, 1985). It was during data analysis that we developed our understandings about the young women who managed to avoid getting pregnant before age 19. Selective sampling of the data assisted us in focusing on and obtaining more information from the five lucky girls.

\section{Results}

The lucky girls who avoided pregnancy unintentionally demonstrate distinct psychosocial processes related to sexual and contraceptive behavior. The lucky girls had limited sexual risk perception, were externally motivated to avoid pregnancy, and complied with decisions made by significant others to initiate sexual activity and to use contraceptives. At times their compliance with partners' wishes meant they did not use contraceptives, and "by God's grace" did not become pregnant.

The five lucky girls described themselves as "quiet and shy" in high school, not being involved in sports or extracurricular activities, and not thinking about their future. Their parents did not talk to them about sex or future goals. They abdicated sexual decision making to their parents, partners, and peers. One lucky girl reported that she consistently used oral contraceptives as mandated by her grandmother. Another lucky girl had sexual intercourse with her steady boyfriend who insisted they use condoms. Another had sexual intercourse for the first time when she was 13 years old because her girlfriend told her she should. None of the lucky girls became pregnant during her adolescent years.

\section{Unaware of Sexual Risks}

The lucky girls did not think about sexual risks or future consequences of risky behavior. One girl said she "just lived from day to day, not thinking about my future." She said, "It was not a conscious decision not to have a baby, it was not on my mind, it wasn't anything you thought of. Babies just weren't on your mind growing up" and "[sexually transmitted] diseases didn't cross my mind." Another girl recalled using condoms, but not because of a conscious awareness of the need to prevent pregnancy or sexually transmitted diseases. She admitted:

[W]e both decided [to use condoms], I guess not to get pregnant. 'Cause diseases didn't cross my mind. I guess it was just the thing we needed to do, because I still don't believe I consciously decided not to have a baby, but it was the thing to do to be safe. And I guess safe includes not having a baby, but at the time it just didn't dawn ...

Lucky girls were more vulnerable to sexual risks as a result of their lack of awareness. 


\section{Motivated by Others}

Authoritative parents and grandparents became the external motivators that encouraged the lucky girls to avoid sexual risks. Although the girls did not discuss sexuality-related issues with their parents, they understood their parents' rules and complied with them. One lucky girl recalled strict protective messages from her parents, who said, "We'll kill you if you bring children into the house,' but they didn't really tell us why." These parents had a protective-authoritative approach to parenting. They told lucky girls what the rules were, but did not encourage two-way communication or teach them how to think.

Interactions with their parents did not help these girls make connections between adult expert knowledge and their own novice experiences, which could have facilitated development of self-regulation. One lucky girl said, "I never would have talked to my father about sex, and I was very hesitant to talk to my mother. They put the fear of God in us, which is probably why I waited until 15 to have sex." Lucky girls were motivated by others and were passive in their response to authoritative communication. A lucky girl accepted what her parents told her as law: "They just said, 'Don't do it' and there was nothing else left to say." Another girl recalled her relationship with her dominant grandmother:

Whatever she said goes. Because when you're living in my grandmother['s] house, whatever she says really goes. ... I didn't have any children while I was younger, because I didn't go the route or take the route that [my mother] took. ... My grandmother made sure I did not go that route. I had no choice.

One lucky girl spoke about her mother not talking to her about sex when she was young and how that put her at greater risk for teenage pregnancy:

My mother never really sat me down and talked about it. So I had to learn through friends, my peers. And now that I'm an adult, I kind of regret that, because I know that I would have made better decisions as a teenager. I think I was just lucky not to get pregnant.

The lucky girls neither integrated expert concepts nor developed independent problem solving.

\section{Complying With Others}

Lucky girls complied with decisions made by their parents, grandparents, partners, and peers. Consequently, they did not develop decision-making skills, which left them vulnerable in sexual situations.

Parents. Lucky girls' parents' and grandparents' decisions were protective. They told the girls to delay sexual activity, but when they were sexually active to use contraceptives. One lucky girl complied with her grandmother's decision for her to avoid sexual risks. She recalled, "I actually didn't make the decision [to avoid early childbearing]. My grandmother made the decision." She used contraceptives consistently because her grandmother required her to protect herself, and she followed her grandmother's rules. She remembered her grandmother talking to her,

She told me [to start birth control] even before I actually started [having sex]. But she didn't stop the sex part, but the child part she could. [She said] if you're going to do it, you're going to have to take some kind of birth control to protect yourself. I was taking a pill.

Externally motivated girls whose parents have made decisions for them are especially vulnerable to sexual risks when they leave home and face decisions without their parents and with others who are not protective of them.

Partners. Lucky girls' partners' decisions were usually protective. Partners usually insisted on contraceptive use, and the girls followed their partners' lead. One lucky girl talked about complying with her boyfriend's plan to wait to have children. She remembered: 

American Females

It depends on how he's feeling. . . . He wants to wait, after he graduates from Morehouse [College], and that'll be 5 years from now. I'd rather wait until both of us decide, or else all of a sudden ... he's not happy about it, and neither am I.

When another lucky girl had sexual intercourse for the first time, she said, "It was not planned. I got caught up in the heat [of the moment], but he did use a condom." She acknowledged her boyfriends were "more insistent than I was" about using contraceptives. She also acknowledged that she was lucky she did not get pregnant. Her boyfriend usually insisted they use condoms. In fact they "used condoms $90 \%$ of the time, the other $10 \%$ [got] caught up in the heat [of the moment]" and "by God's grace [I did not get pregnant]." A lucky girl divulged, "I used contraceptives off and on. I guess God was just really saying 'you are so stupid and I have to do something here to protect you.' I don't know why I never got pregnant."

Peers. Lucky girls had friends who were sexually active and influenced their decisions to become sexually active. Peer decisions were not protective. They encouraged sexual activity, but not contraception. One lucky girl talked about the peer pressure she experienced related to her early sexual activity. She confided, "I just remember being scared. I remember her really, really pressuring me. And I regretted it. It was awful. I can say that I was having sex just to have sex." Another girl reflected on how she was influenced by a girlfriend who was sexually active. She recalled:

I believe she influenced me a lot, too, to go ahead and have sex. I think I asked her, 'What do you think I should do?' I think she did ... [influence me].

Realizing how vulnerable she had been to peer influence, this lucky girl decided she did not want to influence another friend to have sex. She said:

When I figured out that my girlfriend that was having sex influenced me, I didn't want to influ- ence [my other friend] any. So, I just never really discussed it. Because I felt like I might do the same thing to her. That happened between me and my other [sexually active] girlfriend. I told her what I just said, that I think you know my other girlfriend influenced me so I didn't want to influence her.

Although this lucky girl wanted to help her friend, she passively did not try to influence her one way or the other.

\section{Discussion}

We focused this analysis of adolescent pregnancy avoidance on girls who were vulnerable to sexual risks because of their passive compliance with others. Because these lucky girls appear to be at lower sexual risk (contraceptive users in monogamous relationships), they could easily be overlooked in clinical practice.

Passively following the suggestions/rules of significant others, they described themselves as being unaware of sexual risks and, therefore, developed no self-protective strategies. Redfern-Vance and Hutchinson (1995) noted the difficulty in awareness of sexual risks in women with repeat STDs. They described the woman who repeatedly acquired STDs as "abdicating herself" and, related to risky sexual behavior, being "unconscious, disconnected from herself. She is in the world unthinkingly" (p. 226). Like these self-abdicating women, lucky girls were not thinking about protecting themselves from sexual risks. They avoided pregnancy, but it was not intentional.

Viewing social context as the foundation for adolescent pregnancy avoidance is supported by the symbolic interactionist (Hutchinson, 1993), social and cultural capital (Kelly, 1994), and recent adolescent risk behavior perspectives (Resnick et al., 1997). Social context is especially pertinent for adolescents who are not only influenced by, but also abdicate their decisions to, other people. The social context for the lucky girls consisted of protectiveauthoritative parents and grandmothers, inconsistently protective partners, and nonprotective peers who influ- 
enced their passive sexual and contraceptive behavior and ultimately promoted dependence and vulnerability. In contrast, Martyn and Hutchinson (2001) described tough girls who intentionally avoided adolescent pregnancy through a radically different form of social interaction with protective-collaborative parents, partners, and peers. These significant individuals assisted tough girls to develop their own independent thinking and strategies for self-protection. The divergent interaction styles we found between tough girls and lucky girls are similar to those described by Yowell (1997) between early adolescent females, their mothers, and friends.

The lucky girls demonstrated a pattern of interaction with significant adults similar to "the power-assertive communication style and passive engagement style" (p. 187) of some of the girls in Yowell's (1997) study. The "power-assertive" mothers in Yowell's study used "power and authority as the principal means for transmission of rules, regulations, and values concerning sexuality" (p. 179). One of these mothers said: "All the conversations [questions] were easy-I set the ground rules, I have all the power. My daughter may not always agree with me, but she can't always have her way" (p. 179).

Lucky girls' communication with friends was similar to that of the passive girls in Yowell's (1997) study who were not as comfortable talking to their friends about sex and were more concerned with parental authority and a need to "know what was right" (p. 190). Peer pressure experienced by the lucky girls was consistent with Holland and Eisenhart's (1992) research on women attending Southern colleges. They found African-American freshman females were susceptible to manipulation by older female students. In contrast, other researchers have found that friends can facilitate problem-solving abilities (Azmitia, 1988; Perret-Clermont, Perret, \& Bell, 1991), and adolescents tend to explore sexual issues more with friends than with parents (Raffaelli \& Duckett, 1989; Savin-Williams \& Berndt, 1990).

These findings have important implications for practice. Although this descriptive, qualitative study focuses on a small sample, a deeper understanding of how some low-income African-American females unintentionally avoid adolescent pregnancy can be used to inform nursing practice. What happens when these lucky girls are pressured for unwanted and/or unprotected sex? What proactive risk intervention opportunities might we be missing with this group of girls?

\section{How Do I Apply These Findings to Nursing Practice?}

By developing supportive relationships with adolescents like these lucky girls, nurses offer opportunities for "multiplexity" (Kelly, 1994, p. 99) and social support (St. Lawrence et al., 1994) that can facilitate development of responsible sexual behavior. Encouraging other positive influences in girls' lives through participation in extracurricular activities and sports (Miller et al., 1998; Sabo et al., 1999) also should promote intentional avoidance of adolescent pregnancy.

Comprehensive health assessment of African-American, adolescent females that includes psychosocial characteristics, relationship influences, sexual activity, and contraceptive behavior will help identify girls who are at greater sexual risk because of their passive compliance. Once nurses have identified high-risk girls, they can promote development of internal motivation, self-regulation, and decision making with adolescent girls and their parents through education, role modeling, and role-playing related to making connections between expert knowledge and problem-solving skills. Discussion, including strategies for confronting possible risk scenarios and role playing active decision making, should be useful activities for adolescent girls. Including partners and peers in role-playing and problem-solving activities will support lucky girls' development of responsible behavior.

Nurses can promote protective behaviors with lucky girls. Because lucky girls are willing to comply with authoritative adults, developing health-promoting contracts with them as they learn to become autonomous should increase protective behaviors and foster the development of self-protective strategies. A contract established between nurses and adolescent girls to use contraceptives 


\section{Lucky Girls: Unintentional Avoidance of Adolescent Pregnancy Among Low-Income African- American Females}

or to remain abstinent should facilitate compliance with self-protective recommendations from professionals.

Acknowledgment. This research was partially supported by an Epsilon Alpha Chapter Sigma Theta Tau Research Award and a National Organization of Nurse Practitioner Faculties Small Research Award, to Dr. Martyn.

Author contact: kmartyn@umich.edu, with a copy to the Editor: roxie.foster@uchsc.edu

\section{References}

Azmitia, M. (1988). Peer interaction and problem-solving; When are two heads better than one? Child Development, 59(1), 87-96.

Blumer, H. (1969). Symbolic interactionism: Perspective and method. Englewood Cliffs, NJ: Prentice Hall.

Brener, N.D., \& Collins, J.L. (1998). Co-occurrence of health-risk behaviors among adolescents in the United States. Journal of Adolescent Health, 22, 209-213.

Brindis, C. (1999). Building for the future: Adolescent pregnancy prevention. Journal of the American Medical Women's Association, 54, 129-132.

Diaz, R.M., Neal, C., \& Amaya-Williams, M. (1990). The social origins of self-regulation. In L.C. Moll (Ed.), Vygotsky and education: Instructional implications and applications of sociohistorical psychology (pp. 127-1540). New York: Cambridge University Press.

Freeman, E.W., \& Rickels, K. (1993). Early childbearing: Perspectives of Black adolescents on pregnancy, abortion, and contraception. Newbury Park, CA: Sage.

Gilligan, C. (1982). In a different voice: Psychological theory and women's development. Cambridge, MA: Harvard University Press.

Glaser, B.G. (1978). Advances in the methodology of grounded theory: Theoretical sensitivity. Mill Valley, CA: Sociology Press.

Glaser, B.G. (1992). Basics of grounded theory analysis. Mill Valley, CA: Sociology Press.

Gullone, E., \& Moore, S. (2000). Adolescent risk-taking and the fivefactor model of personality. Journal of Adolescence: Special Issue: Adolescent and Risk-Taking, 23, 393-407.

Henshaw, S. (1999). Teenage pregnancy: Overall trends and state-by-state information. New York: Alan Guttmacher Institute.

Holland, D., \& Eisenhart, M.A. (1989). On the absence of women's gangs in two southern universities. In H. Matthews (Ed.), Southern Anthropological Society Proceedings: No. 22. Women in the south (pp. 27-46). Athens, GA: University of Georgia Press.
Hutchinson, S.A. (1993). Grounded theory: The method. In P.L. Munhall \& C.O. Boyd (Eds.), Nursing research: A qualitative perspective (2nd ed., pp. 180-212). New York: National League for Nursing Press.

Kaufman, R.B., Spitz, A.M., Strauss, L.T., Morris, L., Santelli, J.S., Koonin, L.M., \& Marks, J.S. (1998). The decline in U.S. teen pregnancy rates, 1990-1995. Pediatrics, 102, 1141-1147.

Kelly, M.P.F. (1994). Towanda's triumph: Social and cultural capital in the transition to adulthood in the urban ghetto. International Journal of Urban and Regional Research, 18, 88-111.

Li, X., Feigelman, S., \& Stanton, B. (2000). Perceived parental monitoring and health risk behaviors among urban low-income African-American children and adolescents. Journal of Adolescent Health, 27, 43-48.

Lincoln, Y.S., \& Guba, E.G. (1985). Naturalistic inquiry. Beverly Hills, CA: Sage.

Lindberg, L.D., Boggess, S., Porter, L., \& Williams, S. (2000). Teen risktaking: A statistical portrait. Washington, DC: Urban Institute.

Martyn, K.K., \& Hutchinson, S.A. (2001). Low-income African American adolescents who avoid pregnancy: Tough girls who rewrite negative scripts. Qualitative Health Research Joumal, 11, 238-256.

Mead, G.H. (1934). Mind, self and society. Chicago: University of Chicago Press.

Miller, K.E., Sabo, D., \& Farrell, M.P. (1998). Athletic participation and sexual behavior in adolescents: The different worlds of boys and girls. Journal of Health and Social Behavior, 39, 108-123.

Morgan, C., Chapar, G.N., \& Fisher, M. (1995). Psychosocial variables associated with teenage pregnancy. Adolescence, 30, 277-289.

Perret-Clermont, A., Perret, J., \& Bell, N. (1991). The social construction of meaning and cognitive activity in elementary school children. In J.M. Levine, L. Resnick, \& S. Behrend (Eds.), Socially shared cognition (pp. 133-156). New York: American Psychological Association.

Pistella, C.L., \& Bontati, F.A. (1998). Communication about sexual behavior among adolescent women, their family and peers. Families in Society, 79, 206-211.

Raffaelli, M., \& Duckett, E. (1989). "We were just talking. . . ": Conversations in early adolescence. Journal of Youth and Adolescence, 18, 567-582.

Redfern-Vance, N., \& Hutchinson, S.A. (1995). The process of developing personal sovereignty in women who acquire sexually transmitted diseases. Qualitative Health Research, 5, 222-236.

Resnick, M.D., Bearman, P.S., Blum, R.W., Bauman, K.E., Harris, K.M., Jones, J., et al. (1997). Protecting adolescents from harm: Findings from the National Longitudinal Study of Adolescent Health. JAMA, $278,823-832$

Sabo, D.F., Miller, K.E., Farrell, M.P., Melnick, M.J., \& Barnes, G.M. (1999). High school athletic participation, sexual behavior and adolescent pregnancy: A regional study. Journal of Adolescent health, 25, 207-216. 
Savin-Williams, R., \& Berndt, T. (1990). Friendship and peer relations. In S. Feldman \& G. Elliott (Eds.), At the threshold: The developing adolescent (pp. 277-307). Cambridge, MA: Harvard University Press.

Sonenstein, F.L., Ku, L., Lindberg, L.D., Turner, C.F., \& Pleck, J.H. (1998). Changes in sexual behavior and condom use among teenage men: 1988 to 1995. American Journal of Public Health, 88, 956-959.

St. Lawrence, J.S., Brasfield, T.L., Jefferson, K.W., Allyene, E., \& Shirley, A. (1994). Social support as a factor in African-American adolescents' sexual risk behavior. Journal of Adolescent Research, 9, 292-310.

Trent, K., \& Crowder, K. (1997). Adolescent birth intentions, social disadvantage and behavioral outcomes. Journal of Marriage and the Family, 59, 523-535.
Ventura, S.L., Martin, J.A., Curtain, S.C., \& Matthews, T.J. (1998). Births: Final data for 1997. Hyattsville, MD: National Center for Health Statistics.

Vygotsky, L.S. (1962). Thought and language. Cambridge, MA: MTT Press.

Vygotsky, L.S. (1978). Mind in society. Cambridge, MA: Harvard University Press.

Yowell, C. (1997). Risks of communication: Early adolescent girls' conversations with mothers and friends about sexuality. Journal of Early Adolescence, 17, 172-196.

\section{Nursecom journals are now just a
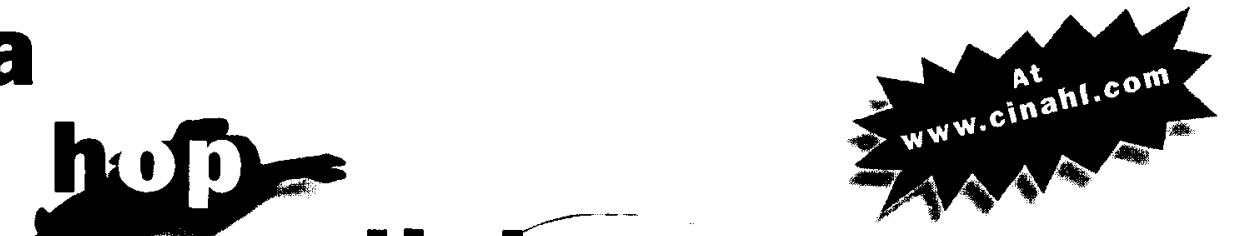

Stup away!

\section{and a}

That's right, for a small fee the full text of Nursecom Inc. journals (1997 on) are available as PDF files on Cinahl's website.

The journals you've always gone to...now come to you!

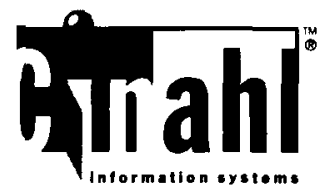

free:

$(800) 959.7167$

telephone:

(818) 409.8005

www.cinahl.com

fax:

(818) 546.5679

e-mail: cinahl@cinahl.com

1509 Wilson Terrace, Glendale CA 91206 